\title{
The Use of Disease-Modifying Agents in Multiple Sclerosis - by the Canadian Network of MS Clinics
}

\author{
Paul O'Connor, Virginia Devonshire for the Canadian Network of MS Clinics
}

Can. J. Neurol. Sci. 2008; 35: 127-129

The following statement relates to the currently available Health Canada approved medications for the treatment of multiple sclerosis (MS): Avonex ${ }^{\circledR}$ (Interferon Beta 1a), Betaseron ${ }^{\circledR}$ (Interferon Beta 1b), Rebif ${ }^{\circledR}$ (Interferon Beta 1a) Copaxone ${ }^{\circledR}$ (Glatiramer Acetate) and Tysabri ${ }^{\circledR}$ (natalizumab). In addition, we suggest considerations for use of mitoxantrone which is not approved for use in MS in Canada but is supported for use in relapsing MS in many other countries.

We believe this statement is required so that all Canadian MS patients who could benefit from such agents will be considered for therapy, with equal access, and regardless of their ability to pay or geographic location in Canada.

There are inherent limitations in using the criteria selected for therapeutic trials as clinical treatment indicators. However the efficacy of disease-modifying therapies outside of the trial treatment groups has not been established and as such these guidelines rely heavily on data from phase 3 trials in MS.

Each province should establish a mechanism to evaluate the funding of treatment for any patient whose neurologist feels they would benefit from disease-modifying therapy despite not meeting the criteria described below.

\section{THE FOLLOWING ARE THE CRITERIA FOR CONSIDERATION OF THERAPY IN ESTABLISHED MS WITH RELAPSES:}

- Patients must have met diagnostic criteria for MS, as per the revised McDonald criteria ${ }^{1}$

- The course of disease must include at least one recent clinical attack in the year prior to therapy or two attacks in the previous two years. ${ }^{2-6}$

- The patient must still be ambulatory (with aids, if necessary).

- The use of natalizumab should ordinarily be considered only in patients who continue to have significant disease activity (relapses or MRI) despite treatment with first-line agents such as interferon or glatiramer acetate. ${ }^{7}$

Exceptionally, natalizumab may be used as a first line agent for cases of aggressive relapsing MS where the risk is felt to be justified. $^{7}$

\section{THE FOLLOWING ARE THE CRITERIA FOR CONSIDERATION OF THERAPY IN CLINICALLY ISOLATED SYNDROMES (CIS):}

Patients must have experienced a documented neurological episode (e.g. optic neuritis, myelitis or brainstem syndrome) that is characteristic of central nervous system demyelination as seen in MS. Clinically non-localizing syndromes do not qualify as a CIS.

A thorough work-up to rule out other potential causes of CIS has been performed and there is "no better explanation" for the neurological presentation.

Patients must be deemed at high risk of having another attack and thus developing established relapsing-remitting MS. The exact definition of 'high-risk' is a subject of ongoing debate but all parties agree this at least implies the presence of multiple asymptomatic T2 lesions on cranial MRI with or without gadolinium enhancement at the time of the CIS.$^{8-10}$

The first attack must have occurred within the past year.

To date, interferon beta-1a (Avonex) (Rebif 22mcg), and beta $-1 \mathrm{~b}$ (Betaseron) have been shown to delay the second attack and therefore clinically definite MS in phase 3 trials. ${ }^{8-10}$

\section{THE FOLLOWING ARE THE CRITERIA FOR CONSIDERATION OF MITOXANTRONE THERAPY IN ESTABLISHED MS WITH RELAPSES:}

Certain patients may have particularly aggressive disease with frequent relapses that do not remit or remit incompletely and which are associated with rapidly increasing neurologic disability. Such patients will have usually attempted treatment with first-line disease modifying agents (interferon-beta or glatiramer acetate) or perhaps natalizumab without adequate disease suppression.

Mitoxantrone therapy can be used to reduce disease activity and slow disability progression in this situation, but this agent, along with other broad-spectrum immunosuppressants, is associated with significantly higher toxicity risks. ${ }^{11}$ Mitoxantrone is associated with cardiomyopathy and the development of malignancy (e.g. leukemia). ${ }^{12}$

- Patients must have evidence of elevated ongoing disease activity, usually despite the use of other disease-modifying therapies, as exemplified by one of the following:

From the Department of Neurology, St. Michael's Hospital (POC), Toronto, ON; University of British Columbia (VD), Vancouver, BC, Canada.

Received July 16, 2007. Final Revisions Submitted November 19, 2007. Reprint requests to: Paul O'Connor, Department of Neurology, St. Michael's Hospital, 30 Bond Street, Toronto, Ontario, M5B 1W8, Canada. 
Multiple (two or more) attacks in the preceding year affecting motor or cerebellar systems with incomplete recovery causing sustained disability worsening.

OR

Rapid ongoing clinical disability progression and MRI evidence of significant active inflammation (i.e. multiple enhancing lesions).

- Physicians treating such patients should have experience in the use of mitoxantrone or other immunosuppressants and should generally be associated with a multidisciplinary MS Clinic that can assist with patient assessment and monitoring, particularly regarding cardiologic and hematologic function.

- The exact treatment regimen to be used in a particular patient should be individualized, with the aim of using the lowest possible effective dose of immunotherapy. The safety of using immunotherapies such as mitoxantrone after natalizumab use has not been established.

\section{ADDITIONAL CONDITIONS THAT APPLY WITH ANY DISEASE-MODIFYING THERAPY USE.}

- Patients must agree to regular follow-up with the prescribing physician.

- Female patients must consent to practice appropriate contraception.

- There must be an established mechanism to assure that proper patient education is given before initiation of treatment, along with proper follow-up to assure compliance and monitor side effects.

- Although these treatments appear to delay progression in the short-term, their long-term efficacy has not been established.

\section{IT IS FURTHER RECOMMENDED THAT:}

- All eligible patients should be considered for therapy early in the course of their disease. Disease-modifying therapies appear to be more efficacious when used earlier. ${ }^{8,10}$

- Periodic review of treated patients should be undertaken to evaluate efficacy and side effects in order to decide upon the appropriateness of continuing treatment.

- Given that persistently high levels of interferon neutralizing antibodies likely reduce efficacy, it is recommended that antibody assessment be considered after a year or more of therapy particularly in patients who are not doing well. ${ }^{13}$ Laboratory testing for such antibodies should be readily available as part of regular patient care.

- It is recognized that the issues involved in use of diseasemodifying therapies in MS are complex and go beyond the usual scope of neurology practice. We therefore recommend that such therapies be prescribed and monitored by neurologists who are experienced in the management of MS patients.

\section{SPECIAL CONSIDERATIONS FOR NATALIZUMAB:}

- The risk of the development of PML remains a significant concern for all patients. Although PML developed in two patients who were on a combination therapy of interferon beta 1a (Avonex $\left.{ }^{\circledR}\right)$ and natalizumab it is unclear if this was the result of the combination therapy or whether the same risk is associated with natalizumab monotherapy. Additionally, patient exposure to natalizumab to date has been limited to 36 months and the risk of PML and other opportunistic infections with longer exposure is unknown.

- There is no certain guideline for a washout period when switching from an interferon or glatiramer acetate. However, no adverse events were seen when beta interferon and natalizumab were used in combination for at least up to 18 months. Prior mitoxantrone or cyclophosphamide use will necessitate a washout period. The duration required is uncertain and will depend on the dose and duration of the prior chemotherapy. This decision will need to be individualized.

- An MRI should be obtained within three months of initiating Tysabri therapy for future comparison should PML be questioned.

- All patients will require close regular clinical follow-up to monitor for signs and symptoms of PML. Patients should be seen at a minimum of every six months. The value of routine MRI screening for PML is unclear. The product monograph contains an algorithm to use when PML is suspected. There is no known value in testing for serum JC virus either diagnostically or as a predictive screening measure.

- The development of persistent antibodies to natalizumab reduces its efficacy and causes an increase in infusion reactions. Access to antibody testing should be made readily available and testing should be considered if infusion reactions develop or if the efficacy of the drug is questioned. Antibody conversion is typically seen between two and six months.

\section{CONSIDERATIONS FOR DISCONTINUING THERAPIES}

- Therapies should be discontinued (as opposed to switched) in individuals who are unlikely to benefit from them due to their more advanced disability level (i.e. non-ambulatory).

- It is recognized the MS gradually evolves from a dominant early inflammatory phase, in which current therapies have the opportunity to maximize their benefit, to a more degenerative phase that has not been shown to be affected by these antiinflammatory agents. The transition between these two phases is gradual and characterized by a reduction in clinical attacks and MRI enhancement together with a slow increase in physical disability. Discontinuation should therefore be considered in patients who have not experienced an attack for several years and have continued to experience an increase in disability.

This consensus statement was prepared by Drs. P. O'Connor and V. Devonshire with input and approval from the following neurologist members of the Canadian Network of MS clinics:

Antel J, Arnold D, Bhan V, Bar-Or A, Bakker J, Bell R, Boyle C, Brunet D, Costello F, Duquette P, Freedman M, Gomori A, Grand-Maison F, Gray TA, Hader W, Hohol M, Hrebicek O, Hooge J, Kremenchutzky M, Lee L, Marrie RA, Murray J, Myles ML, Metz L, Oger J, Patry DG, Prat A, Rabinovitch H, Short C, Smyth P, Traboulsee A, Vorobeychik G.

\section{REFERENCES}

1. Polman CH, Reingold SC, Edan G, Filippi M, Hartung HP, Kappos L, et al. Diagnostic criteria for multiple sclerosis: 2005 revisions to the McDonald Criteria. Ann Neurol. 2005; 58(6):840-6. 
2. IFNB Multiple Sclerosis Study Group. Interferon beta-1b is effective in relapsing-remitting multiple sclerosis. I. Clinical results of a multicenter, randomized, double-blind, placebocontrolled trial. Neurology. 1993; 43:655-61.

3. Jacobs LD, Cookfair DL, Rudick RA, Herndon RM, Richert JR, Salazar AM, et al. Intramuscular interferon beta-1a for disease progression in relapsing multiple sclerosis. Ann Neurol. 1996; 39:285-94

4. PRISMS Study Group. Randomized double-blind placebocontrolled study of interferon [beta]-1a in relapsing/remitting multiple sclerosis. Lancet. 1998; 352:1498-504.

5. Johnson K, Brooks B, Cohen JA, Ford CC, Goldstein R, Lisak RP, et al. Copolymer 1 reduces relapse rate and improves disability in relapsing-remitting multiple sclerosis: results of a phase III multicenter, double-blind, placebo-controlled trial. Neurology. $1995 ; 45: 1268-76$.

6. Polman $\mathrm{CH}$, O'Connor PW, Haverdova E, Hutchinson M, Kappos $\mathrm{L}$, Miller DH, et al. A randomized, placebo-controlled trial of natalizumab for relapsing multiple sclerosis. N Engl J Med. 2006; Mar 2:354(9):899-910.

7. Health Canada-Product Monograph 2006.

8. Jacobs LD, Beck RW, Simon JH, Kinkel RP, Brownscheidle CM, Murray TJ, et al. Intramuscular interferon beta-1a therapy initiated during a first demyelinating event in multiple sclerosis. N Engl J Med. 2000; 343:898-904.

9. Comi G, Filippi M, Barkhof F, Durelli L, Edan G, Fernandez O, et al. Effect of early interferon treatment on conversion to definite multiple sclerosis: a randomized study. Lancet. 2001; 357: 1576-82.
10. Kappos L, Polman CH, Freedman MS, Edan G, Hartung HP, Miller $\mathrm{DH}$, et al. Treatment with interferon beta- $1 \mathrm{~b}$ delays conversion to clinically definite and McDonald MS in patients with clinically isolated syndromes. Neurology. 2006; 10;67(7):1242-9.

11. Hartung HP, Gonsette R, Konig N, Kwiecinski H, Guseo A, Morrissey SP, et al. Mitoxantrone in progressive multiple sclerosis: a placebo-controlled, double-blind, randomized, multicentre trial. Lancet. 2002; 360(9350):2018-25.

12. Goodin DS, Arnason BG, Coyle PK, Frohman EM, Paty DW. Therapeutics and Technology Assessment Subcommittee of the American Academy of Neurology. The use of mitoxantrone (Novantrone) for the treatment of multiple sclerosis: report of the Therapeutics and Technology Assessment Subcommittee of the American Academy of Neurology. Neurology. 2003; 61(10): 1332-8.

13. Goodin DS, Frohman EM, Hurwitz B, O'Connor PW, Oger JJ, Reder AT, et al. Neutralizing antibodies to interferon beta: assessment of their clinical and radiographic impact: an evidence report: report of the Therapeutics and Technology Assessment Subcommittee of the American Academy of Neurology. Neurology. 2007; 68(13):977-84. 